\title{
RESEARCH
}

\section{The LIM homeodomain protein ISL1 mediates the function of TCF7L2 in pancreatic beta cells}

\author{
Weijuan Shao', Vivian Szeto'2, Zhuolun Song', Lili Tian', Zhong-Ping Feng'2, M Cristina Nostro2,3,4 and \\ Tianru Jin1,2,4,5 \\ 1Division of Advanced Diagnostics, Toronto General Research Institute, University Health Network, Toronto, Ontario, Canada \\ 2Department of Physiology, University of Toronto, Medical Sciences Building, Toronto, Ontario, Canada \\ ${ }^{3}$ Division of Experimental Therapeutics, Toronto General Research Institute, University Health Network, Toronto, Ontario, Canada \\ ${ }^{4}$ McEwen Centre for Regenerative Medicine, University Health Network, Toronto, Ontario, Canada \\ ${ }^{5}$ Banting and Best Diabetes Center, University of Toronto, Toronto, Ontario, Canada
}

Correspondence should be addressed to T Jin: tianru.jin@utoronto.ca

\begin{abstract}
Pancreatic $\beta$-cell $T c f 7 / 2$ deletion or its functional knockdown suggested the essential role of this Wnt pathway effector in controlling insulin secretion, glucose homeostasis and $\beta$-cell gene expression. As the LIM homeodomain protein ISL1 is a suggested Wnt pathway downstream target, we hypothesize that it mediates metabolic functions of TCF7L2. We aimed to determine the role of ISL1 in mediating the function of TCF7L2 and the incretin hormone GLP-1 in pancreatic $\beta$-cells. The effect of dominant negative TCF7L2 (TCF7L2DN) mediated Wnt pathway functional knockdown on Is/1 expression was determined in $\beta T C F D N$ mouse islets and in the rat insulinoma cell line INS-1 832/13. Luciferase reporter assay and chromatin immunoprecipitation were utilized to determine whether Is/1 is a direct downstream target of Tcf7/2. TCF7L2DN adenovirus infection and siRNA-mediated $I s / 1$ knockdown on $\beta$-cell gene expression were compared. Furthermore, Is/1 knockdown on GLP-1 stimulated $\beta$-catenin $\mathrm{S} 675$ phosphorylation and insulin secretion was determined. We found that TCF7L2DN repressed ISL1 levels in $\beta T C F D N$ islets and the INS-1 832/13 cell line. Wnt stimulators enhanced $/ s / 1$ promoter activity and binding of TCF7L2 on Is/1 promoter. TCF7L2DN adenovirus infection and Is/1 knockdown generated similar repression on expression of $\beta$-cell genes, including the ones that encode GLUT2 and GLP-1 receptor. Either TCF7L2DN adenovirus infection or $/ s / 1$ knockdown attenuated GLP-1-stimulated $\beta$-catenin 5675 phosphorylation in INS-1 832/13 cells or mouse islets and GLP-1 stimulated insulin secretion in INS-1 832/13 or MIN6 cells. Our observations support the existence of TCF7L2-ISL1 transcriptional network, and we suggest that this network also mediates $\beta$-cell function of GLP-1.
\end{abstract}

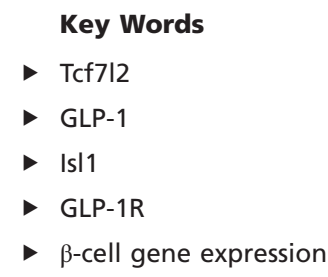

Journal of Molecular Endocrinology (2018) 61, 1-12

\section{Introduction}

Following the recognition that TCF7L2 is a type 2 diabetes (T2D) risk gene by intensive and reproducible genome-wide association studies (GWAS) (Florez et al. 2006, Grant et al. 2006), great efforts have been made to explore functions of this Wnt signaling pathway effector in pancreatic $\beta$-cells and elsewhere (Schafer et al. 2007, Norton et al. 2011, 2014, Ip et al. 2012, 2015, Kaminska et al. 2012, Jin 2016). Previous in vitro and ex vivo investigations 
have collectively suggested the role of mouse and human TCF7L2 in facilitating $\beta$-cell proliferation and regulating $\beta$-cell metabolic functions (da Silva Xavier et al. 2009, Shu et al. 2009, 2012). Although the investigations on the three different pancreatic $\beta$-cell Tcf $712^{-/-}$mouse models have generated inconsistent observations (Boj et al. 2012, da Silva Xavier et al. 2012, Mitchell et al. 2015), functional knockdown of the Wnt signaling cascade with dominant negative TCF7L2 (TCF7L2DNin humans and mice) in pancreatic $\beta$-cells by our group and by another team allowed us to suggest that TCF7L2 in mice is important for $\beta$-cell gene expression and function (Takamoto et al. 2014, Shao et al. 2015).

Utilizing RNAseq in human pancreatic islets and the rodent insulinoma cell line, Zhou et al. suggested recently that the LIM homeodomain protein ISL1 is among the primary downstream targets of TCF7L2 and the existence of the TCF7L2-ISL1 transcriptional network (Zhou et al. 2014).

In rodent species, ISL1 was shown to be expressed in pancreatic $\alpha, \beta, \delta$ and PP cells (Karlsson et al. 1990, Dong et al. 1991, Ahlgren et al. 1997). A previous study by $\mathrm{Du}$ et al. revealed that Isl1-deficient pancreatic endocrine precursors cannot form functional islet cells and that $\beta$-cell specific Isl1-/- mice were diabetic (Du et al. 2009). Several follow-up investigations have then revealed the role of ISL1 in regulating the expression of pancreatic islet genes including MafA, Arx, Pdx1 and Slc2a2 (Glut2) (Liu et al. 2011, Hunter et al. 2013, Ediger et al. 2014), and that ISL1 may cooperate with LIM domain binding 1 (LDB1) in exerting its regulatory functions in pancreatic islets (Hunter et al. 2013, Ediger et al. 2016), including the maintenance of the terminally differentiated state of pancreatic $\beta$-cells (Ediger et al. 2016).

To determine whether ISL1 also mediates the function of the Wnt signaling pathway effector $\beta$-catenin $(\beta$-cat)/TCF and GLP-1 in rodent pancreatic $\beta$-cells, here we assessed the effect of TCF7L2DN expression on Isl1 mRNA and ISL1 protein levels in our BTCFDN mouse model (Shao et al. 2015), and in the rat insulinoma cell line INS-1 832/13. We have also compared the effect of adenovirus-mediated TCF7L2DN expression and siRNA-mediated Isl1 knockdown on $\beta$-cell gene expression, as well as high glucose (HG) and HG plus GLP-1 stimulated insulin secretion. Our observations have collectively confirmed the existence of the TCF7L2ISL1 transcriptional network in rodent islets. More importantly, our investigations have expanded this novel network study into the function of the incretin hormone GLP-1, on which a series of diabetes drugs have been generated during the past decade (Shigeto et al. 2015, Wu et al. 2015, Tian \& Jin 2016).

\section{Materials and methods}

\section{Cell cultures and experimental mice}

The rat insulinoma cell line INS-1 832/13, the mouse MIN6 cell line and mouse pancreatic islets were cultured as previously described (Shao et al. 2010). No mycoplasma contamination has been verified in these two cell lines. Mouse islets were isolated by a collagenase-based method from 6- to 8-week-old male C57BL6/J mice (The Jackson Laboratory) as described previously (Shao et al. 2013b). The generation of the transgenic mouse line $\beta T C F D N$ has been presented previously, via mating TCF $7 L 2 D N_{\text {Tet }}$ with Ins2-rtTA (Shao et al. 2015). The pregnant mothers were fed with doxycycline diet provided by Harlan $(625 \mathrm{mg} /$ $\mathrm{kg}$ doxycycline, TD.08434) until weaning. After weaning and genotype clarification at age of 3 weeks, both $\beta T C F D N$ and the wild-type littermate controls were fed with the doxycycline diet before the experiments were performed (Shao et al. 2015). Male BTCFDN mice and littermate wild-type controls at the age of 6-8 weeks were utilized for pancreatic islets isolation. Mice were maintained in pathogen-free cages at room temperature and relative humidity of $50 \%$, with free access to food and water under a $12 \mathrm{~h}$ light/darkness cycle. Up to five mice were kept per cage. All animal protocols were approved by the Institutional Animal Care and Use Committee of the University of Health Network.

\section{Reagents and plasmid}

Recombinant human protein Wnt-3a was the product of R\&D Systems (5036-WN). The Wnt signaling pathway inhibitor iCRT14 was purchased from Sigma-Aldrich. GLP1(7-37) is the product of Abcam. Small interfering RNAs (siRNA) recognizing either a scrambled sequence or Isl1 were provided by Ambion Thermo Fisher Scientific. $p G L 3$ Isl1 Luc plasmid was kindly provided by Dr Chunyan Zhou (Department of Biochemistry and Molecular Biology, School of Basic Medical Sciences, Peking University, China) (Lu et al. 2014).

\section{Western blotting and immunohistochemistry (IHC) studies}

Methods for Western blotting and IHC have been described previously (Shao et al. 2010, Ip et al. 2015). Antibodies 
Table 1 Antibodies utilized in the study.

\begin{tabular}{|c|c|c|}
\hline Antibody & Company & Catalog number \\
\hline$\beta$-Actin & Cell Signaling Technology & 3700 \\
\hline TCF7L2 & Cell Signaling Technology & 2569 \\
\hline$p$ - $\beta$-Catenin & Cell Signaling Technology & 9567 \\
\hline ISL1 & Abcam & Ab109517 \\
\hline $\mathrm{HA}$ & Covance Research Products Inc. & MMS-101P-200 \\
\hline GAPDH & Santa Cruz Biotechnology & 25778 \\
\hline
\end{tabular}

utilized in this study are listed in Table 1. Among them, the TCF7L2 antibody was shown to recognize the long and short isoforms (78 kDa and $58 \mathrm{kDa}$, respectively) of both human and mouse TCF7L2 (Shao et al. 2015). For Western blotting, a 1:1000 dilution solution was made for each of the antibodies. For IHC, a 1:10,000 dilution solution was prepared for the Isl1 antibody.

\section{Quantitative RT-PCR (real-time RT-PCR or qRT-PCR)}

RNAs were extracted from the INS-1 832/13 cell line or isolated mouse pancreatic islets, following the indicated treatment, with the use of the TRI Reagent (SigmaAldrich). Complementary DNA (cDNA) was synthesized using a High-Fidelity cDNA Synthesis Kit (Applied Biosystems), as described previously (Ip et al. 2015). Realtime PCR was performed with the use of SensiFAST SYBR (Bioline Reagents Ltd., London, UK) and a 7900 Fast Real-
Time PCR System (Applied Biosystems). Primers utilized in this study and sizes of the qRT-PCR products are listed in Table 2. Levels of given mRNA were normalized to the levels of the house keeping gene GAPDH.

\section{The generation of adenovirus}

The control adenovirus Ad-GFP, the one that expresses wild-type TCF7L2 (Ad-TCF7L2WT or Ad-TCFWT), and the one that expresses dominant negative TCF7L2 (Ad-TCF7L2DN or Ad-TCFDN) were generated using the AdEasy XL Adenoviral Vector System (Agilent Technologies). As described previously (Ip et al. 2015), this adenovirus system co-expresses the green fluorescence protein (GFP) and the designated target protein. The INS-1 $832 / 13$ cell line or isolated mouse islets were infected with the correspondent adenovirus $\left(1 \times 10^{7} \mathrm{pfu}\right)$ for $48 \mathrm{~h}$, followed by indicated treatment.

\section{Luciferase reporter assay}

Transfection of luciferase (LUC) reporter plasmids into the mouse MIN6 cells was achieved using $2 \mu \mathrm{g}$ of polyethylenimine (Sigma) and $1 \mu \mathrm{g}$ LUC reporter gene construct in 12-well plates. Luciferase (LUC) reporter analyses were performed using firefly luciferin substrate

Table 2 Primers utilized in the study.

\begin{tabular}{l} 
Gene (mouse/rat) \\
\hline Insulin1 \\
Insulin2 (rat) \\
Insulin2 (mouse) \\
Axin2 \\
Glp1r \\
Gipr \\
Mafa (mouse) \\
Mafa (rat) \\
Pdx1 \\
Ngn3 \\
Isl1 \\
Gapdh (rat) \\
Gapdh (mouse) \\
Nkx6.1 (rat) \\
Nkx6.1 (mouse) \\
Tcf7 (mouse) \\
Tcf7 (rat) \\
Isl1 promoter \\
Slc2a2 \\
TCF7L2 (mouse) \\
Tcf7l2 (rat) \\
TCF7L2 (human) \\
C-Myc \\
Cyclin D1 \\
\end{tabular}

\begin{tabular}{l} 
Sequen \\
\hline Forward \\
\hline 5-GCAAGCAGGTCATTGTTCCA-3 \\
5-GCAAGCAGGTCATTGTTCCA-3 \\
5-CATCAGCAAGCAGGAAGCCTATCT-3 \\
5-TCCTGACCAAACAGACGACG-3 \\
5-GGGTCTCTGGCTACATAAGGA-3 \\
5-AACCATCTTGATCAATTTCCTCATC-3 \\
5-ACAGAAAGAAGTCGGGTGCG-3 \\
5-GTATCCATGTCCGTGCGGG-3 \\
5-CAGTGGGCAGGAGGTGCTTA-3 \\
5-TCGGGAGAACTAGGATGGCG-3 \\
5-CTGAGGGTTTCTCCGGATTTG-3 \\
5-AGCTCATTTCCTGGTATGACAA-3 \\
5-GACCACAGTCCATGCCATCA-3 \\
5'-TGGGAAGAGAAAACACACCA-3' \\
5'-GAGAAAACACACCAGACCC-3' \\
5'-TGCTGGGATCTGGTGTACCT-3' \\
5'-AGTGGCATGTACAAAGAGACTG-3' \\
5'-TGGCATTTAAGAAAAGCAT-3' \\
5'-AACAGCCTCTCGTTGACTGG-3' \\
5'-AGGAACGACAGCTTCACATG-3' \\
5'-TCCATATTACCCGCTGTCGC-3' \\
5'-TCGCCTGGCACCGTAGGACA-3' \\
5'-GCTCGCCCAAATCCTGTA-3' \\
5'-ATGTGAAGTTCATTTCCA-3' \\
\hline
\end{tabular}


(BioShop, Burlington, ON, Canada) as described previously (Ip et al. 2015).

\section{Chromatin immunoprecipitation (ChIP)}

The ChIP procedure has been described in our previous study (Ip et al. 2015). Following ChIP, PCR was performed using primers recognizing the Isl1 promoter surrounding the TCF binding site, as provided in Table 2.

\section{Insulin secretion assay}

For the INS-1 832/13 cell line, we followed the method by Deisl et al. for measuring insulin secretion (Deisl et al. 2013). Briefly, INS1 832/13 cells were subject to siRNAmediated Isl1 knockdown for $48 \mathrm{~h}$. After an equilibration period of $2 \mathrm{~h}$ in the KRB with $2.8 \mathrm{mM}$ glucose, cells were incubated for $60 \mathrm{~min}$ in fresh KRB buffer containing $2.8 \mathrm{mM}$ glucose (defined as low glucose, LG), $16.7 \mathrm{mM}$ glucose (defined as $\mathrm{HG}$ ), or $16.7 \mathrm{mM}$ glucose plus $10 \mathrm{nM}$ GLP-1. Supernatants were then harvested for insulin detection with the insulin enzyme immunoassay kit (AIS, Hong Kong) (Shao et al. 2015). For the MIN6 cell line, cells were incubated in KRB with $2.0 \mathrm{mM}$ glucose for $6 \mathrm{~h}$, followed by $30 \mathrm{~min}$ incubation with $2.8 \mathrm{mM}$ glucose (LG), $25 \mathrm{mM}$ glucose (HG) or HG plus $10 \mathrm{nM} \mathrm{GLP-1.} \mathrm{For}$ cellular insulin content determination, cells from each of the treatment groups were harvested, followed by insulin content detection with the above kit. Values for cellular insulin content were normalized against cellular protein content. Insulin secretion in each group of cells was presented as percentage of cellular insulin content in $60 \mathrm{~min}$ (for INS-1 832/13) or $30 \mathrm{~min}$ (for MIN6).

\section{Calcium imaging}

Fura-2 ratiometric $\mathrm{Ca}^{2+}$ sensitive dye was used to measure intracellular $\mathrm{Ca}^{2+}$ levels in single cells, as described previously (Gardzinski et al. 2007). INS-1 832/13 cells were pre-loaded with Fura- 2 AM (5 $\mu \mathrm{M}$, Molecular Probes) in dark for $40 \mathrm{~min}$. Fura-2 $\mathrm{Ca}^{2+}$ signal was acquired at alternate excitation wavelengths of 340 and $380 \mathrm{~nm}$, while cells were perfused with the control/loading solution containing $120 \mathrm{mM} \mathrm{NaCl}, 3.5 \mathrm{mM} \mathrm{KCl}, 1 \mathrm{mM}$ $\mathrm{MgCl}, 0.4 \mathrm{mM} \mathrm{KH}_{2} \mathrm{PO}_{4}, 5 \mathrm{mM} \mathrm{NaHCO}_{3}$ and $1.3 \mathrm{mM} \mathrm{CaCl}_{2}$ (pH: 7.3-7.4), adjusted to $2.8 \mathrm{mM}$ glucose, $16.7 \mathrm{mM}$ glucose or $16.7 \mathrm{mM}$ glucose with or without 10 nM GLP-1. Signals were digitized by an intensified charged-coupled device camera (PTI), and fluorescence intensity ratios were calculated using EasyRatioPro. Response to stimulus was quantified by extracting and evaluating the change in $\mathrm{F} / \mathrm{F}_{0}$ before and after each stimulus. Results are normalized to the response to $2.8 \mathrm{mM}$ glucose (Gardzinski et al. 2007, Soltani et al. 2011).

\section{Statistics}

All results are expressed as mean \pm s.D. Statistical significance was assessed by the Student's $t$-test or by oneway ANOVA. $P$ value less than 0.05 was considered to be statistically significant.

\section{Results}

\section{TCF7L2DN-mediated $\beta$-cat/TCF functional knockdown leads to reduced Isl1 expression}

We reported previously that in $\beta T C F D N$ mouse islets, PDX1- and NKX6.1-positive pancreatic islet cell numbers were reduced (Shao et al. 2015). With both qRT-PCR and Western blotting approaches, we show here that in $\beta T C F D N$ mouse islets, both Isl1 mRNA and ISL1 protein levels were reduced (Fig. 1A and B). $\beta T C F D N$ mice also showed approximately $10 \%$ reduction of ISL1-positive pancreatic islet cells, assessed by the immunohistochemistry approach (Supplementary Fig. 1, see section on supplementary data given at the end of this article).

As ISL1 is known to be expressed in other pancreatic islet cells, we cannot attribute the observed reduction fully to pancreatic $\beta$-cells. Further investigations were then conducted in the clonal insulinoma cell line INS-1 832/13 with adenovirus-mediated TCF7L2DN expression. For this purpose, INS-1 832/13 cells were infected with adenovirus that expresses wild-type TCF7L2 or TCF7L2DN, generated in our previous study (Ip et al. 2015) (Fig. 1C), followed by Western blotting and qRT-PCR. As shown in Fig. 1D and E, Ad-TCF7L2DN infection reduced ISL1 expression at both protein and mRNA levels. Ad-TCF7L2WT infection, however, increased Isl1 mRNA levels (Fig. 1E) although we did not see appreciable activation on ISL1 protein expression (Fig. 1D). Thus, similar to the INS-1 832/13 cell Tcf7l2 depletion model presented by Zhou et al. (Zhou et al. 2014), in vivo or in vitro TCF7L2DN expression also reduces ISL1 expression in rodent pancreatic $\beta$-cells.

\section{ISL1 is likely a direct downstream target of $\beta$-cat/TCF7L2}

Mouse Isl1-LUC reporter gene plasmid (Lu et al. 2014) was then utilized to test whether ISL1 promoter activity 
A

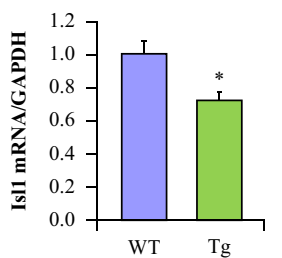

B
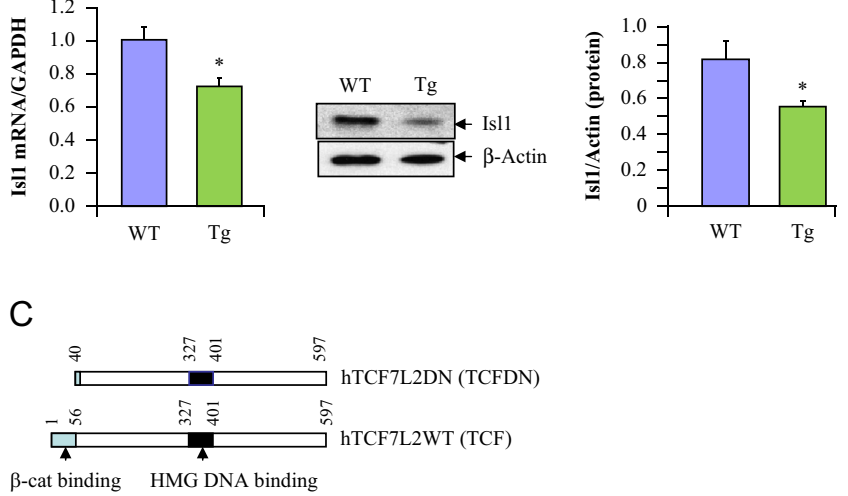

D
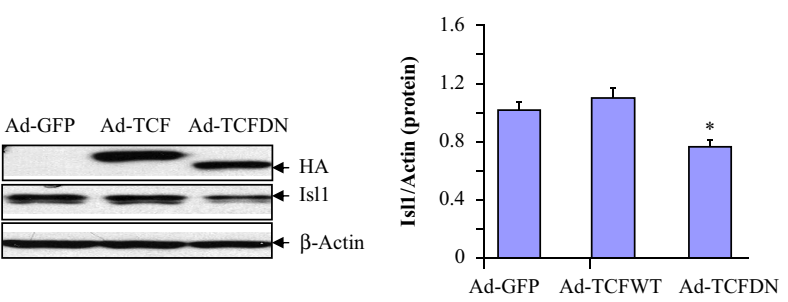

$E$

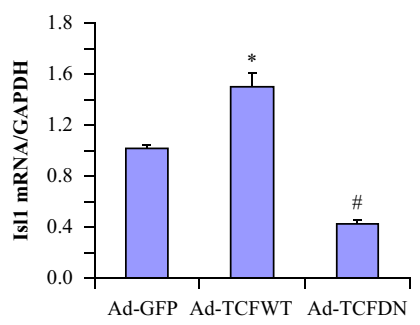

Figure 1

TCF7L2DN-mediated $\beta$-cat/TCF functional knockdown leads to reduced ISL1 expression. (A and B) Comparison of Is/1 mRNA and ISL1 protein expression in $\beta T C F D N$ (Tg) and littermate control (WT) mouse islets. (C) Schematic of constructs of human Ad-TCF7L2DN (TCFDN) and Ad-TCF7L2 (TCF). The $\beta$-catenin interaction domain and the DNA binding HMG domain are illustrated. (D and E) Detection of ISL1 protein and Is/1 mRNA expression in INS-1 832/13 cells infected with Ad-TCF7L2DN or Ad-TCF7L2. HA antibody detects adenovirus expressed exogenous TCF7L2 or TCF7L2DN. $n=3$ for panels A, B and E. Panel D is a representative blot for 3 independent Western blotting experiments. * or \#, $P<0.05$. Values are represented as mean \pm S.D. A full color version of this figure is available at https://doi.org/10.1530/JME-17-0181.

can be affected by Wnt pathway activation or inhibition. We were unable to transfect this Isl1-LUC fusion plasmid into the INS-1 832/13 cell line with a desirable efficiency and then switched to the MIN6 cell line. Figure 2A shows that in MIN6 cells, Isl1-LUC activity can be stimulated by Wnt3a or lithium chloride ( $\mathrm{LiCl})$ treatment. iCRT14, a chemical inhibitor of the $\beta$-cat/TCF signaling (Marlow et al. 2013), repressed Isl1-LUC and blocked Wnt3a or $\mathrm{LiCl}$ induced activation (Fig. 2A). The co-transfection of the constitutively active S33Y $\beta$-cat mutant (Ni et al. 2003) generated a robust activation on Isl1-LUC (Fig. 2B), while Ad-TCF7L2DN infection repressed Isl1-LUC expression (Fig. 2C).

An evolutionarily conserved TCF binding motif was located within the Isl1 promoter region, designated as TBE1 (Fig. 2D) (Lu et al. 2014). Via the utilization of the ChIP approach in the INS-1 832/13 cell line, we found that TCF7L2 antibody, but not the control IgG, precipitated DNA fragment that contains TBE1 (Supplementary Fig. 2). We define this as the indication of the interaction between TCF7L2 and TBE1. Figure 2E/F shows our qChIP results, indicating that the interaction between TCF7L2 and TBE1 was stimulated by Wnt3a treatment or exogenous TCF7L2 expression but repressed by TCF7L2DN expression. These observations collectively suggest that ISL1 is likely a directly downstream target of TCF7L2 in mouse pancreatic $\beta$-cells.

Unexpectedly, Wnt3a treatment generated no appreciable effect on ISL1 protein expression in the INS-1 832/13 cell line (Fig. 2G). We repeated the experiment with $16 \mathrm{~h}$ Wnt3a treatment in INS-1 832/13 cells and performed the same Wnt3a treatment in mouse islets. Again we did not see the stimulation on ISL1 protein level (Supplementary Fig. 3). We then tested effects of $\beta$-cat/ TCF activity inhibition with iCRT14 and stimulation with S33Y $\beta$-cat expression in the INS-1 832/13 cell line. As shown in Fig. 2H and I, iCRT14 treatment repressed, while S33Y $\beta$-cat expression stimulated ISL1 protein expression, supporting our suggestion that $\beta$-cat/TCF positively regulates $\beta$-cell ISL1 expression.

\section{TCF7L2DN expression and /s/1 knockdown generate similar effect on $\beta$-cell gene expression}

We found previously that Ad-TCF7L2DN infection in the INS-1 832/13 cell line repressed the expression of $P d x 1$, Nkx6.1 and other $\beta$-cell genes (Shao et al. 2015). Here, we conducted the adenovirus infection experiments in both the INS-1 832/13 cell line and mouse pancreatic islets, and expanded the qRT-PCR examination to include endogenous $T c f 7 l 2, T c f 7$, genes that encode GLP-1 receptor (Glp1r), GIP receptor (Gipr) and Glut2. The virus infection in mouse pancreatic islets was monitored by visualizing GFP $48 \mathrm{~h}$ after the adenovirus infection and HA-tagged protein detection with Western blotting (Supplementary Fig. 4). Figure 3A and B shows that in both INS-1 832/13 cell line and mouse islets, TCF7L2DN expression did not reduce endogenous $T c f 7 l 2$ or $T c f 7$ expression. 
A

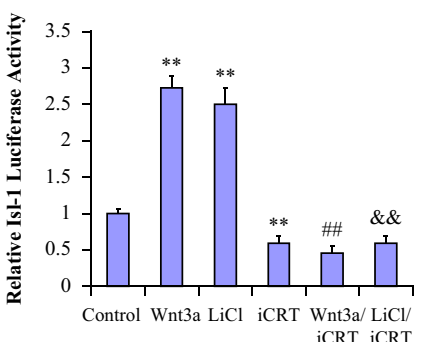

D

TBE1

Hu AGTGAGGGTGC TTTGTGG ATCTCAA M AGTGAGGGTCC TTTGTGG GTCTCAA R AGTGAGGATCC TTTGTGG GTCTCAA
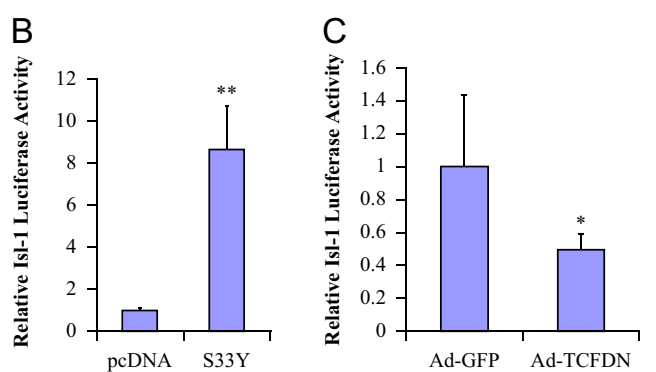

E

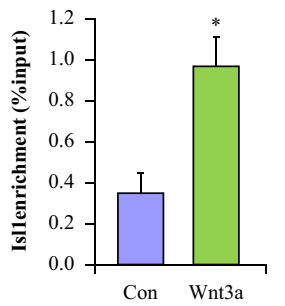

F

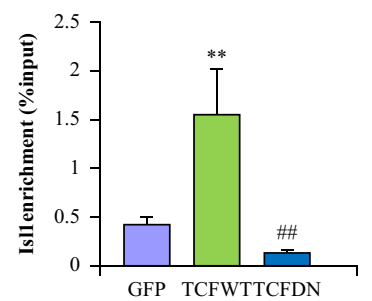

$\mathrm{H}$

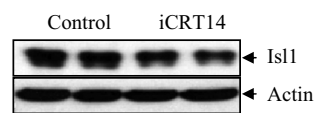

I
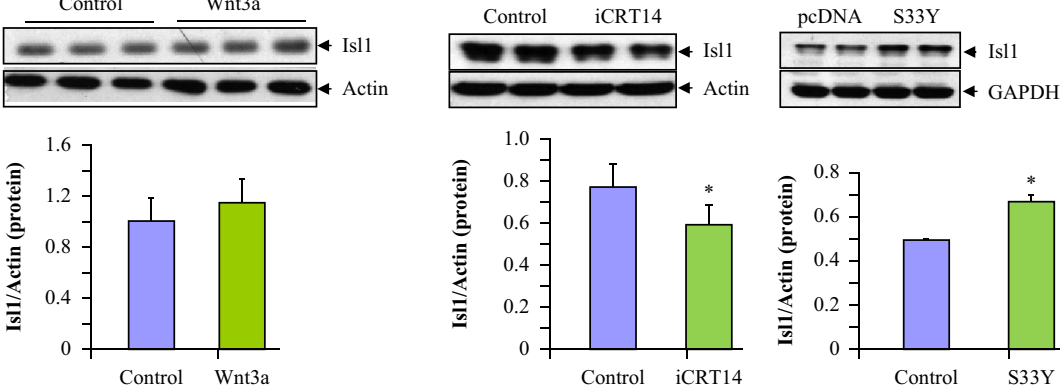

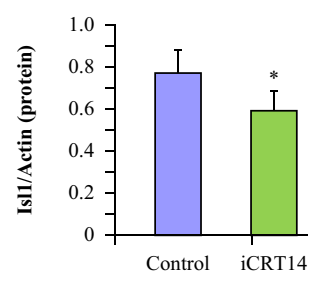

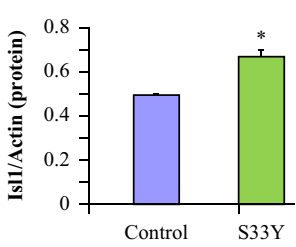

Figure 2

ISL1 is likely a direct downstream target of the Wnt signaling cascade in pancreatic $\beta$-cells. (A, B and C) Is/1-LUC reporter activities in the mouse MIN6 cell line. (A) MIN6 cells were transfected with $I s / 1-L U C$ reporter gene plasmid $(1 \mu \mathrm{g})$ for $18 \mathrm{~h}$, followed by indicated treatment for $4 \mathrm{~h}$. iCRT14 (iCRT, $10 \mu \mathrm{M})$ is a $\beta$-cat/TCF signaling inhibitor. The dosage for Wnt3a was $25 \mathrm{nM}$ and for $\mathrm{LiCl}$ was $10 \mathrm{mM}$. (B) MIN6 cells were co-transfected with Is/1-LUC $(1 \mu \mathrm{g})$ and the control plasmid (pcDNA3) or the $\beta$-cat S33Y mutant $(1 \mu \mathrm{g})$ for $18 \mathrm{~h}$. (C) MIN6 cells were infected with indicated adenovirus for $48 \mathrm{~h}$ and meanwhile, Is/1-LUC reporter gene plasmid $(1 \mu \mathrm{g})$ was transfected into the cells. Panels A, B and C are representative data of three independent experiments performed in triplicates. (D) The illustration of putative TCF/LEF1 binding site (designated as TBE1) in human ( $\mathrm{Hu}$ ) and rodent ( $\mathrm{M}$ for mouse and $\mathrm{R}$ for rat) ISL1/Is/1 gene promoters. (E/F) qChIP shows the effect of Wnt3a $(E)$ and Ad-TCF virus infection (F) on the binding of TCF7L2 to TBE1. (G, H and I) The effect of Wnt3a treatment (G), iCRT14 $(\mathrm{H})$ treatment or S33Y $\beta$-cat (S33Y) (I) expression on Isl1 protein levels in the INS- $1832 / 13$ cell line. $n=3$ for panels $\mathrm{E}, \mathrm{F}, \mathrm{G}, \mathrm{H}$ and I. *; $P<0.05$. ** or \#\#; $P<0.01$. Values are represented as mean \pm S.D. A full color version of this figure is available at https://doi. org/10.1530/JME-17-0181.
The expression of a battery of $\beta$-cell genes including Glp1r, Gipr and Glut2 were repressed by Ad-TCF7L2DN expression. siRNA-mediated Isl1 knockdown was then performed in the INS-1 832/13 cell line. Figure 3C shows that expression of tested $\beta$-cell genes, including Glp1r, Gipr and Glut2 was also repressed by Isl1 knockdown. The similar repression pattern on $\beta$-cell gene expression via Ad-TCF7L2DN infection and Isl1 knockdown allows us to suggest that SL1 mediates the function of $\beta$-cat/TCF7L2 on $\beta$-cell gene expression. As anticipated, Isl1 knockdown did not affect the expression of Tcf7l2 or Tcf7 (Fig. 3C), as ISL1 is likely downstream of the bipartite transcription factor $\beta$-cat/TCF.

To further verify that ISL1 mediates the effect of TCF7L2 on Glp1r expression, we tested the stimulation on Glp1r expression by Ad-TCF7L2 infection in the INS-1 832/13 cell line (Fig. 4A) and observed that the stimulation can be blocked by simultaneous Isl1 gene knockdown (Fig. 4B).

\section{GLP1 stimulated $\beta$-cat $\mathbf{S 6 7 5}$ phosphorylation and insulin secretion can be attenuated by Is/1 knockdown}

The repressive effect on Glp1r level by either TCF7L2DN expression or Isl1 knockdown prompted us to ask whether ISL1 mediates $\beta$-cell function of the incretin hormone GLP1. In pancreatic $\beta$-cells, $\beta$-cat/TCF activity can be stimulated by GLP1 as this incretin hormone stimulates $\beta$-cat S675 phosphorylation (Liu \& Habener 2008, Shao et al. 2013a). We repeated the observation by Liu et al. (Liu \& Habener 2008) that GLP1 (10 nM) can stimulate $\beta$-cat S675 phosphorylation in the INS-1 832/13 cell line, and demonstrated that this stimulation can be blocked with siRNA-mediated Isl1 knockdown (Fig. 5A). Figure 5B and $\mathrm{C}$ shows that in both the INS-1 832/13 cell line and mouse pancreatic islets, adenovirus-mediated TCF7L2DN expression also attenuated GLP1-stimulated $\beta$-cat S675 phosphorylation. 
A

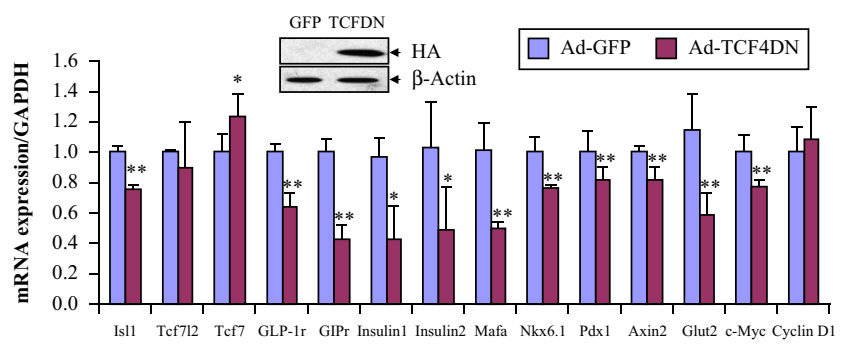

B

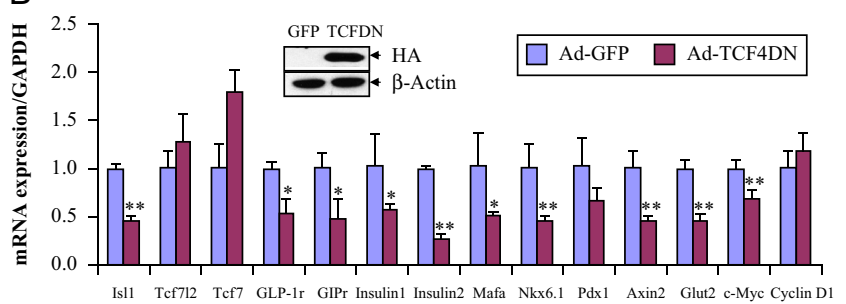

C

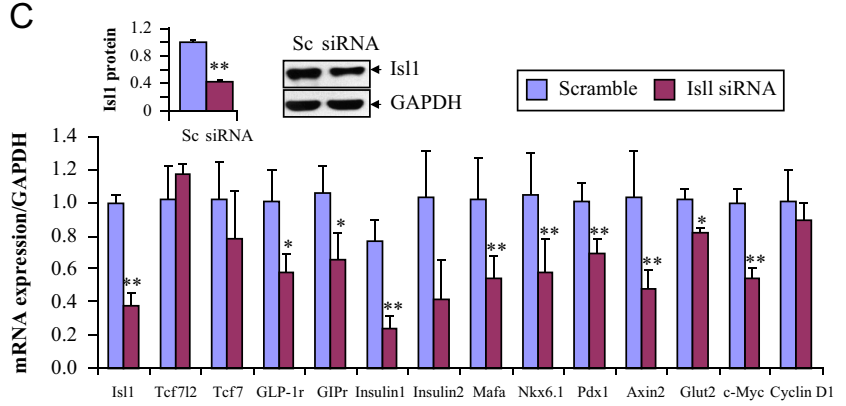

Figure 3

Is/1 knockdown mimics the effect of TCF7L2DN expression on $\beta$-cell gene expression. (A) INS-1 832/13 cells were infected for $48 \mathrm{~h}$ with either the control adenovirus (GFP) or AdTCF7L2DN (TCFDN). (B) Mouse islets were infected for $48 \mathrm{~h}$ with either the control adenovirus (GFP) or AdTCF7L2DN (TCFDN). (C) siRNA-mediated Is/1 knockdown was performed in the INS-1 $832 / 13$ cells. $n=3$ for panels $A, B$ and $C$. ${ }^{*} P<0.05 ; * * P<0.01$. Values are represented as mean \pm S.D. A full color version of this figure is available at https://doi.org/10.1530/JME-17-0181.

We then assessed the effect of Isl1 knockdown on glucose and GLP1 regulated insulin secretion. In the INS-1 $832 / 13$ cell line with our insulin secretion assay protocol, HG as well as HG plus GLP1- (10 nM) stimulated insulin secretion were recognizable (Fig. 5D), but were not as profound as we observed previously in mouse islets (Shao et al. 2015). Nevertheless, following siRNA-mediated Isl1 knockdown, it appeared that HG plus GLP-1-facilitated insulin secretion was attenuated, when compared with cells transfected with the scramble siRNA (Fig. 5D/E).

We have also tested whether Isl1 knockdown reduces calcium influx in the INS-1 832/13 cell line in response to HG and GLP-1 treatment, with the ratiometric Fura-2
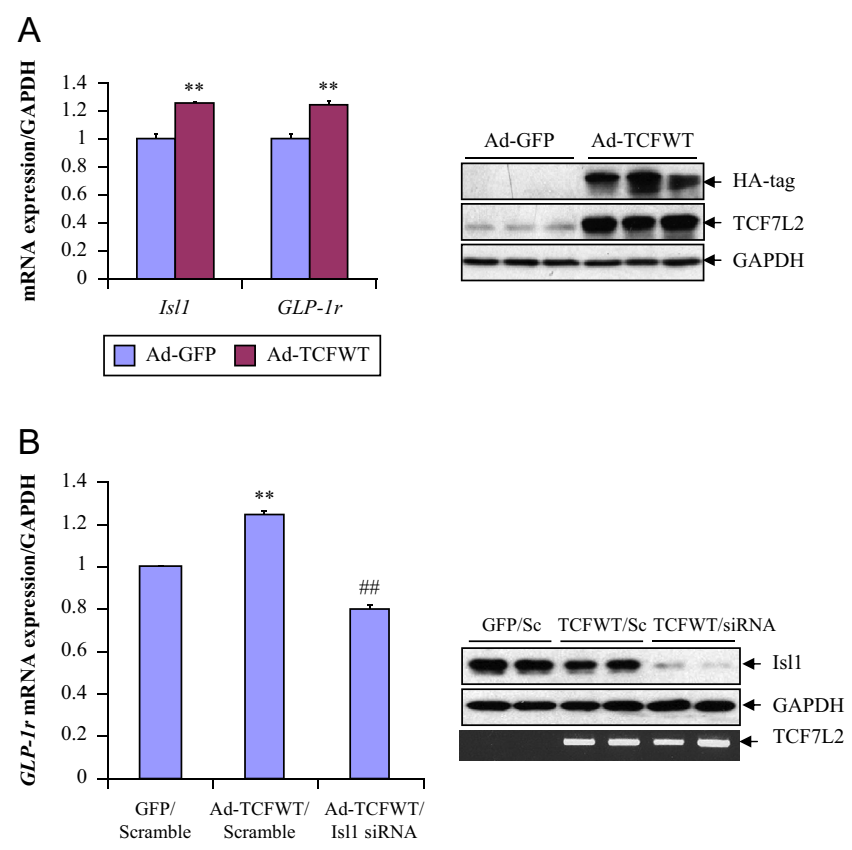

\section{Figure 4}

Is/1 mediates the stimulation on GIp1r expression by TCF7L2 overexpression. (A) Ad-TCF7L2 (Ad-TCFWT) infection in the INS-1 832/13 cell line increased $I s / 1$ mRNA expression, accompanied with increased G/p1r mRNA level. The right panel shows the detection of TCF7L2/Tcf7/2 (the $78 \mathrm{kDa}$ long isoform) by Western blotting $48 \mathrm{~h}$ after indicated virus infection with the HA tag antibody or the TCF7L2 antibody. (B) In INS-1 832/13 cells, simultaneous Is/1 knockdown (with siRNA against Is/1) attenuated the stimulation of TCF7L2 over-expression (Ad-TCFWT infection) on Glp1r mRNA level. The right panel shows the verification of siRNA-mediated $I s / 1$ knockdown by Western blotting and the detection of adenovirus infection mediated TCF7L2 expression by RT-PCR. ** or \#\#; $P<0.01$. $n=3$ for Panels A and B. A full color version of this figure is available at https://doi.org/10.1530/JME-17-0181.

$\mathrm{Ca}^{2+}$ imaging assays. In INS-1 832/13 cells treated with scrambled siRNA, HG or HG plus GLP-1 enhanced calcium influx as compared to low glucose treatment (Fig. 5F and $\mathrm{G}, n=16)$. In this cell line treated with Isl1 siRNA, HG or HG plus GLP-1-enhanced calcium influx was attenuated (Fig. 5F and G, $n=16$ ). Representative traces of INS-1 cells treated with scrambled siRNA and Isl1 siRNA are shown in Fig. 5F. $\mathrm{KCl}(50 \mathrm{mM}$ for $15 \mathrm{~s})$ was then applied to cells at the end of the experiments to confirm that cells are viable.

As the stimulatory effect of HG on insulin secretion in the INS-1 832/13 cell line was relatively moderate, we tested the effect of Isl1 knockdown in the MIN6 cell line. The knockdown efficiency on Isl1 protein expression in this cell line was presented in Fig. 6A. Figure 6B/C shows that after Isl1 knockdown, HG (25 mM) or HG plus GLP1stimulated insulin secretion was attenuated. 
A
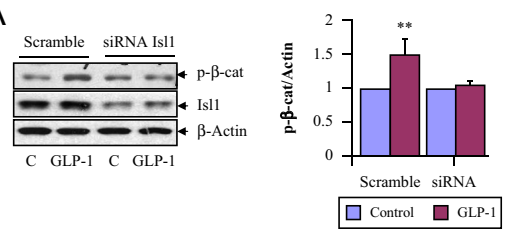

B
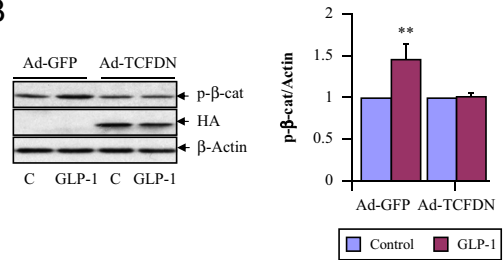

C
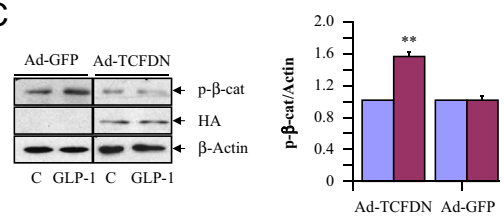

$\square$ Control $\quad \square$ GLP-1

\section{D}

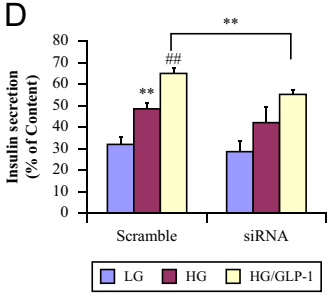

$\mathrm{F}$
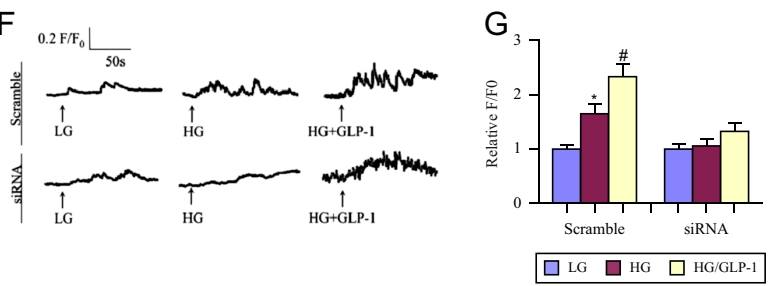

Figure 5

Is/1 knockdown attenuates the effect of GLP1 on $\beta$-cat $\$ 675$ phosphorylation as well as GLP1 stimulated insulin secretion. (A) Effect of siRNA-mediated Is/1 knockdown on GLP-1 (10 nM) stimulated $\beta$-cat S675 phosphorylation in the INS-1 832/13 cell line. (B and C) Effect of Ad-TCF7L2DN (Ad-TCFDN) infection on GLP1 (10 nM) stimulated $\beta$-cat S675 phosphorylation in the INS-1 832/13 cell line (B) and in mouse islets (C). A, B and C show representative blot of three independent experiments. (D/E) Assessment of the effect of $I s / 1$ knockdown on glucose (LG vs HG) or HG plus GLP-1 (10 nM) induced insulin secretion in the INS-1 $832 / 13$ cell line. Panel $E$ shows the insulin contents in cells received control (Scramble) or Is/1 siRNA transfection. ( $F$ and G) HG or HG plus GLP-1 enhanced calcium influx was attenuated in INS-1 832/13 cells after Is/1 knockdown. (F) Representative 340/380 ratio traces of INS-1 cells after scrambled siRNA (top panel) or Is/1 siRNA (bottom panel) treatment. (G) Average change in 340/380 ratio values to HG, and HG plus GLP-1 induced calcium influx, normalized to LG response in INS-1 cells treated with scrambled siRNA or $I s / 1$ siRNA. $n=5$ for Panel D. $n=16$ for Panel G. * or \#; $P<0.05 ; * * ; P<0.01$. * or **, GLP1 treatment vs control for Panels A, B and C, or HG vs LG for Panels D and F; \# or \#\#, HG plus GLP-1 vs HG, for Panels D and G. A full color version of this figure is available at https:// doi.org/10.1530/JME-17-0181.
A
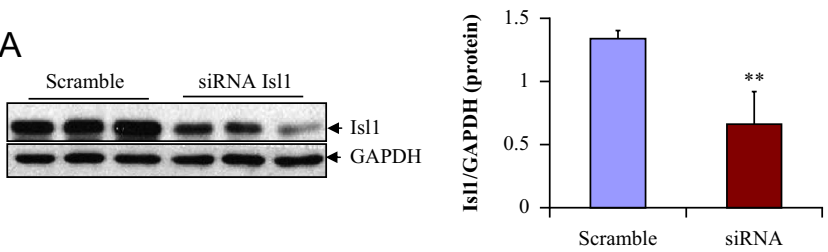

B

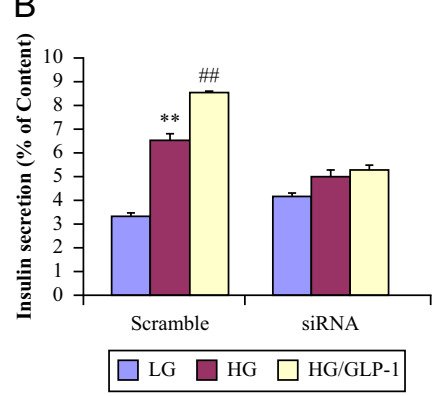

C

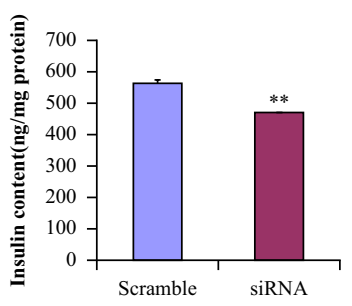

\section{Figure 6}

Is/1 knockdown attenuates the effect of HG plus GLP1 on insulin secretion in the MIN6 cell line. (A) The effect of Is/1 knockdown on ISL1 protein expression, assessed by Western blotting. (B/C) Assessment of Is/1 knockdown on HG ( $25 \mathrm{mM})$ and HG plus GLP1 (HG/GLP1, 10 nM) on insulin secretion in the MIN6 cell line. $n=3$ for Panel A and $n=5$ for Panel B/C. For Panel B, **, HG vs LG; \#\#, HG plus GLP1 vs HG. A full color version of this figure is available at https://doi.org/10.1530/JME-17-0181.

\section{Discussion}

Since 2006, reproducible GWAS have shown that TCF7L2 is a T2D risk gene (Florez et al. 2006, Grant et al. 2006, Cauchi et al. 2007). To explore metabolic functions of this Wnt pathway effector, efforts have been made in assessing its role in the liver, adipose tissues and pancreatic islets with various tools (Lyssenko et al. 2007, Schafer et al. 2007, Norton et al. 2011, Boj et al. 2012, Savic et al. 2013, Jin 2016).

As discussed previously, different functional outcomes were reported on assessing mouse models with $\beta$-cell Tcf7l2 deletion (Boj et al. 2012, da Silva Xavier et al. 2012, Mitchell et al. 2015, Shao et al. 2015). To resolve the potential discrepancy, we and another team employed a functional knockdown approach via TCF7L2DN expression in pancreatic $\beta$-cells (Takamoto et al. 2014, Shao et al. 2015). The advantages with TCF7L2DN include the avoid of the compensation by different TCF members and the potential bi-directional functional feature of a TCF member (Jin 2016). When the RIP promoter was utilized to drive the expression of the mouse TCF7L2DN, the generated transgenic mouse lines showed impaired glucose tolerance and decreased insulin secretion, associated with a marked reduction of $\beta$-cell mass and decreased expression of a battery of $\beta$-cell genes (Takamoto et al. 2014). We generated $\beta T C F D N$ in which TCF7L2DN 


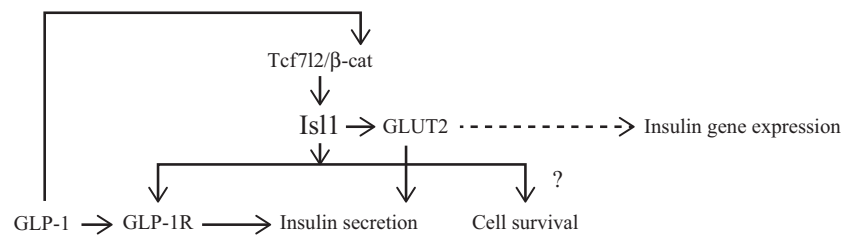

\section{Figure 7}

Illustration of our current understanding on the role of ISL1 in mediating the function of $\beta$-cat/TCF7L2 and GLP1. In mouse pancreatic $\beta$-cells, ISL1 is a direct downstream target of the Wnt signaling pathway effector $\beta$-cat/ TCF7L2. ISL1 mediates the function of TCF7L2 on insulin secretion, possibly involving the regulation of GLP1R and GLUT2 expression in mouse pancreatic $\beta$-cells. Furthermore, the stimulatory effect of GLP1 on $\beta$-cat/TCF activation (via $\beta$-cat $\mathbf{S 6 7 5}$ phosphorylation) can be attenuated due to ISL1 repression, as ISL1 positively regulates GLP1R expression. Finally, GLP1 is known to protect $\beta$-cells against apoptosis. Whether the TCF7L2/ISL1 transcriptional network also mediates the function of GLP1 on $\beta$-cell survival needs to be further examined (indicated with the question mark). The stimulatory effect of ISL1 on insulin gene expression via GLUT2 is shown with dotted arrow.

expression was driven by the Ins 2 promoter, inducible upon doxycycline feeding. $\beta T C F D N$ shows impaired glucose tolerance and reduced $\beta$-cell mass in adulthood when TCF7L2DN expression was induced during the embryonic developmental stage by doxycycline feeding starting in their pregnant mothers (Shao et al. 2015). Attenuated response to GLP-1-stimulated insulin secretion was also shown in $\beta T C F D N$ islets, associated with reduced expression of a battery of $\beta$-cell genes, including $P d x 1$, Nkx6.1, Mafa, Ins1, Ins2, Ngn3, Glp1r and Gipr (Shao et al. 2015).

Here, we expanded the investigation by including the LIM homeobox gene Isl1, a $\beta$-cat/TCF downstream target identified previously in other cell lineages (Lin et al. 2007, Lu et al. 2014) and suggested very recently by Zhou et al. with RNAseq in human islets (Zhou et al. 2014). We show here the repressive effect of TCF7L2DN on ISL1 in both the $\beta T C F D N$ mouse islets and in the INS-1 832/13 cell line.

Our examinations with the LUC reporter assay and qChIP collectively suggest that Isl1 is likely a direct downstream target of $\beta$-cat/TCF7lL2 in mouse pancreatic $\beta$-cells, involving the binding of $\beta$-cat/TCF7L2 on TBE1, a conserved cis-element within the human ISL1 and mouse Isl1 gene promoters. The stimulation on Isl1 promoter activity was observed with the Wnt ligand Wnt3a, the GSK-3 inhibitor LiCl, and the constitutively active S33Y $\beta$-cat mutant. Wnt3a treatment, however, generated no stimulation on mouse ISL1 at protein level. This could be due to the off-target effect of the recombinant Wnt3a as a chemical reagent, or the existence of yet-tobe-identified negative feedback loop on ISL1 expression at the protein level. Indeed, we are far away from clear on the overlapping, redundant or even opposite effect of 19 Wnt ligands on a given target gene in a given tissue, or an organ, or a cell lineage. As ISL1 protein expression was repressed by iCRT14 and stimulated by S33Y $\beta$-cat, we suggest that it is a direct downstream target of $\beta$-cat/TCF, the key canonical Wnt signaling pathway effector.

We suggest that ISL1 serves as the key mediator for $\beta$-cat/TCF7L2 in regulating $\beta$-cell gene expression as AD-TCF7L2DN infection and siRNA-mediated Isl1 knockdown generated similar repressive effect on $\beta$-cell gene expression. More importantly, we revealed that ISL1 knockdown attenuated the effect of the incretin hormone GLP1 in pancreatic $\beta$-cells. As illustrated in Fig. 7, ISL1 is a downstream target of $\beta$-cat/TCF712 and its expression can also be positively regulated by GLP1 via stimulating $\beta$ cat $\mathbf{S 6 7 5}$ phosphorylation. In addition, GLP1R expression can be positively regulated by $\beta$-cat/TCF7L2, likely using ISL1 as a mediator, although the molecular mechanism underlying this regulation is yet to be determined. Whether this signaling cascade also plays a role for GLP1 to exert its other pancreatic $\beta$-cell functions, such as the stimulation of $\beta$-cell survival signaling pathway, as well as the exertion of PKA, Epac and other signaling cascade-mediated insulin secretion, remains to be further investigated (Brubaker \& Drucker 2004, Holz \& Chepurny 2005, Kolic \& MacDonald 2015, Shigeto et al. 2015, Wu et al. 2015, Takeda et al. 2016).

ISL1 was initially identified as a Wnt pathway downstream target in cardiac cells. The loss of Wnt/ $\beta$ cat signaling in anterior heart field resulted in defective outflow tract and fright ventricle development, associated with the decrease in ISL1 positive progenitor cells, while Wnt gain of function led to the expansion of ISL1-positive progenitor cells (Cohen et al. 2007). Transcriptional stimulation of ISL1 expression by Wnt activation was then demonstrated with the cellular models including the embryonic carcinoma cell line P19 (Lin et al. 2007, Lu et al. 2014). ISL1 was also claimed as a direct downstream target of forkhead transcription factors in second-heartfield-derived mesoderm (Kang et al. 2009). Although ISL1 was reported as the first insulin gene enhancer (Karlsson et al. 1990), scientists paid less attention to its $\beta$-cell function when comparing with that of PDX1 and NKX6.1, possibly for its expression in other pancreatic endocrine cell lineages as well (Dong et al. 1991, Du et al. 2009, Liu et al. 2011, Hunter et al. 2013, Ediger et al. 2014, 2016). Considering the recognition of ISL1 in regulating islet gene expression (Liu et al. 2011, Hunter et al. 2013, Ediger et al. 2014), the TCF7L2/ISL1 transcriptional network (Zhou et al. 2014), and our current study showing its role 
in mediating the function of GLP1, we suggest that more attention needs to be paid in the future for this islet cell transcription factor.

It is worth to mention that a recent study shows that $\beta$-cells from Gipr--- mice display greater sensitivity to apoptosis and markedly lower islet expression of Tcf7 (Campbell et al. 2016). We observed reduced Gipr expression but not Tcf7 expression after TCF7L2DN expression or siRNA-mediated Isl1 knockdown. Further investigations are needed to clarify the relationship among the 3 TCF members (Columbus et al. 2010), ISL1, as well as 2 incretin receptors in mediating the function of the two incretin hormones in pancreatic $\beta$-cells. We, however, cannot properly detect pancreatic TCF7 or TCF7L1 expression with reliable antibodies by Western blotting (Columbus et al. 2010).

In summary, we presented in the current study that ISL1 is a direct downstream target of $\beta$-cat/TCF in pancreatic $\beta$-cells, and it is among the mediators of human and mouse TCF7L2in exerting its metabolic functions including $\beta$-cell gene expression. Our investigation has not only verified the existence of TCF7L2/ISL1 transcriptional network in rodent islet $\beta$-cells, but also expanded the implication of this network into the function of the incretin hormone GLP-1.

\section{Supplementary data}

This is linked to the online version of the paper at https://doi.org/10.1530/ JME-17-0181.

\section{Declaration of interest}

The authors declare that there is no conflict of interest that could be perceived as prejudicing the impartiality of the research reported.

\section{Funding}

The study is supported by the Canadian Institutes of Health Research (MOP 89987 to T J). L T is the recipient of Banting and Best Diabetes Centre Post-Doctoral Fellowship. Zhuolun Song is supported by a Banting and Best Diabetes Centre graduate studentship. V S is supported by a Natural Sciences and Engineering Research Council of Canada Graduate Scholarship.

\section{Author contribution statement}

$\mathrm{T} J$ is the guarantor of the study and, as such, has full access to all the data in the study and takes the responsibility for the integrity of the data and the accuracy of the data analysis. W S, V S, Z S, C N and L T have conducted the study and contributed the data for the manuscript. T J, C N, and Z P F designed the experiments. W S and T J have drafted the manuscript. T J, $\mathrm{CN}$ and Z P F have edited the manuscript. All authors have approved the version for the submission.

\section{Acknowledgements}

The authors thank Dr Chunyan Chou in Beijing University (Beijing, P.R. China) for providing the mouse Is/1-LUC fusion gene plasmid.

\section{References}

Ahlgren U, Pfaff SL, Jessell TM, Edlund T \& Edlund H 1997 Independent requirement for ISL1 in formation of pancreatic mesenchyme and islet cells. Nature 385 257-260. (https://doi.org/10.1038/385257a0)

Boj SF, van Es JH, Huch M, Li VS, Jose A, Hatzis P, Mokry M, Haegebarth A, van den Born M, Chambon P, et al. 2012 Diabetes risk gene and Wnt effector Tcf712/TCF4 controls hepatic response to perinatal and adult metabolic demand. Cell 151 1595-1607. (https:// doi.org/10.1016/j.cell.2012.10.053)

Brubaker PL \& Drucker DJ 2004 Minireview: glucagon-like peptides regulate cell proliferation and apoptosis in the pancreas, gut, and central nervous system. Endocrinology 145 2653-2659. (https://doi. org/10.1210/en.2004-0015)

Campbell JE, Ussher JR, Mulvihill EE, Kolic J, Baggio LL, Cao X, Liu Y, Lamont BJ, Morii T, Streutker CJ, et al. 2016 TCF1 links GIPR signaling to the control of beta cell function and survival. Nature Medicine 22 84-90. (https://doi.org/10.1038/nm.3997)

Cauchi S, El Achhab Y, Choquet H, Dina C, Krempler F, Weitgasser R, Nejjari C, Patsch W, Chikri M, Meyre D, et al. 2007 TCF7L2 is reproducibly associated with type 2 diabetes in various ethnic groups: a global meta-analysis. Journal of Molecular Medicine $\mathbf{8 5}$ 777-782. (https://doi.org/10.1007/s00109-007-0203-4)

Cohen ED, Wang Z, Lepore JJ, Lu MM, Taketo MM, Epstein DJ \& Morrisey EE $2007 \mathrm{Wnt} /$ beta-catenin signaling promotes expansion of Isl-1-positive cardiac progenitor cells through regulation of FGF signaling. Journal of Clinical Investigation 117 1794-1804. (https:// doi.org/10.1172/JCI31731)

Columbus J, Chiang Y, Shao W, Zhang N, Wang D, Gaisano HY, Wang Q, Irwin DM \& Jin T 2010 Insulin treatment and high-fat diet feeding reduces the expression of three Tcf genes in rodent pancreas. Journal of Endocrinology 207 77-86. (https://doi.org/10.1677/JOE-100044)

da Silva Xavier G, Loder MK, McDonald A, Tarasov AI, Carzaniga R, Kronenberger K, Barg S \& Rutter GA 2009 TCF7L2 regulates late events in insulin secretion from pancreatic islet beta-cells. Diabetes 58 894-905. (https://doi.org/10.2337/db08-1187)

da Silva Xavier G, Mondragon A, Sun G, Chen L, McGinty JA, French PM \& Rutter GA 2012 Abnormal glucose tolerance and insulin secretion in pancreas-specific Tcf712-null mice. Diabetologia 55 2667-2676. (https://doi.org/10.1007/s00125-012-2600-7)

Deisl C, Simonin A, Anderegg M, Albano G, Kovacs G, Ackermann D, Moch H, Dolci W, Thorens B, M AH, et al. 2013 Sodium/hydrogen exchanger NHA2 is critical for insulin secretion in beta-cells. PNAS 110 10004-10009. (https://doi.org/10.1073/pnas.1220009110)

Dong J, Asa SL \& Drucker DJ 1991 Islet cell and extrapancreatic expression of the LIM domain homeobox gene isl-1. Molecular Endocrinology 5 1633-1641. (https://doi.org/10.1210/mend-5-111633)

Du A, Hunter CS, Murray J, Noble D, Cai CL, Evans SM, Stein R \& May CL 2009 Islet-1 is required for the maturation, proliferation, and survival of the endocrine pancreas. Diabetes 58 2059-2069. (https://doi.org/10.2337/db08-0987)

Ediger BN, Du A, Liu J, Hunter CS, Walp ER, Schug J, Kaestner KH, Stein R, Stoffers DA \& May CL 2014 Islet-1 is essential for pancreatic beta-cell function. Diabetes 63 4206-4217. (https://doi.org/10.2337/ db14-0096)

Ediger BN, Lim HW, Juliana C, Groff DN, Williams LT, Dominguez G, Liu JH, Taylor BL, Walp ER, Kameswaran V, et al. 2016 LIM domainbinding 1 maintains the terminally differentiated state of pancreatic 
beta cells. Journal of Clinical Investigation 127 215-229. (https://doi. org/10.1172/JCI88016)

Florez JC, Jablonski KA, Bayley N, Pollin TI, de Bakker PI, Shuldiner AR, Knowler WC, Nathan DM, Altshuler D \& Diabetes Prevention Program Research Group 2006 TCF7L2 polymorphisms and progression to diabetes in the Diabetes Prevention Program. New England Journal of Medicine 355 241-250. (https://doi.org/10.1056/ NEJMoa062418)

Gardzinski P, Lee DW, Fei GH, Hui K, Huang GJ, Sun HS \& Feng ZP 2007 The role of synaptotagmin I C2A calcium-binding domain in synaptic vesicle clustering during synapse formation. Journal of Physiology 581 75-90. (https://doi.org/10.1113/ jphysiol.2006.127472)

Grant SF, Thorleifsson G, Reynisdottir I, Benediktsson R, Manolescu A, Sainz J, Helgason A, Stefansson H, Emilsson V, Helgadottir A, et al. 2006 Variant of transcription factor 7-like 2 (TCF7L2) gene confers risk of type 2 diabetes. Nature Genetics 38 320-323. (https://doi. org/10.1038/ng1732)

Holz GG \& Chepurny OG 2005 Diabetes outfoxed by GLP-1? Science STKE 2005 pe2. (https://doi.org/10.1126/stke.268205pe2)

Hunter CS, Dixit S, Cohen T, Ediger B, Wilcox C, Ferreira M, Westphal H, Stein R \& May CL 2013 Islet alpha-, beta-, and delta-cell development is controlled by the Ldb1 coregulator, acting primarily with the islet-1 transcription factor. Diabetes 62 875-886. (https:// doi.org/10.2337/db12-0952)

Ip W, Shao W, Chiang YT \& Jin T 2012 The Wnt signaling pathway effector TCF7L2 is upregulated by insulin and represses hepatic gluconeogenesis. American Journal of Physiology: Endocrinology and Metabolism 303 E1166-E1176. (https://doi.org/10.1152/ ajpendo.00249.2012)

Ip W, Shao W, Song Z, Chen Z, Wheeler MB \& Jin T 2015 Liver-specific expression of dominant-negative transcription factor 7-like 2 causes progressive impairment in glucose homeostasis. Diabetes 64 1923-1932. (https://doi.org/10.2337/db14-1329)

Jin T 2016 Current understanding on role of the Wnt signaling pathway effector TCF7L2 in glucose homeostasis. Endocrine Reviews $\mathbf{3 7}$ 254-277. (https://doi.org/10.1210/er.2015-1146)

Kaminska D, Kuulasmaa T, Venesmaa S, Kakela P, Vaittinen M, Pulkkinen L, Paakkonen M, Gylling H, Laakso M \& Pihlajamaki J 2012 Adipose tissue TCF7L2 splicing is regulated by weight loss and associates with glucose and fatty acid metabolism. Diabetes $\mathbf{6 1}$ 2807-2813. (https://doi.org/10.2337/db12-0239)

Kang J, Nathan E, Xu SM, Tzahor E \& Black BL 2009 Isl1 is a direct transcriptional target of Forkhead transcription factors in secondheart-field-derived mesoderm. Developmental Biology 334 513-522. (https://doi.org/10.1016/j.ydbio.2009.06.041)

Karlsson O, Thor S, Norberg T, Ohlsson H \& Edlund T 1990 Insulin gene enhancer binding protein Isl-1 is a member of a novel class of proteins containing both a homeo- and a Cys-His domain. Nature 344 879-882. (https://doi.org/10.1038/344879a0)

Kolic J \& MacDonald PE 2015 cAMP-independent effects of GLP-1 on beta cells. Journal of Clinical Investigation 125 4327-4330. (https:// doi.org/10.1172/JCI85004)

Lin L, Cui L, Zhou W, Dufort D, Zhang X, Cai CL, Bu L, Yang L, Martin J, Kemler R, et al. 2007 Beta-catenin directly regulates Islet1 expression in cardiovascular progenitors and is required for multiple aspects of cardiogenesis. PNAS 104 9313-9318. (https://doi. org/10.1073/pnas.0700923104)

Liu Z \& Habener JF 2008 Glucagon-like peptide-1 activation of TCF7L2dependent Wnt signaling enhances pancreatic beta cell proliferation. Journal of Biological Chemistry 283 8723-8735. (https://doi. org/10.1074/jbc.M706105200)

Liu J, Hunter CS, Du A, Ediger B, Walp E, Murray J, Stein R \& May CL 2011 Islet-1 regulates Arx transcription during pancreatic islet alphacell development. Journal of Biological Chemistry 286 15352-15360. (https://doi.org/10.1074/jbc.M111.231670)
Lu H, Li Y, Wang Y, Liu Y, Wang W, Jia Z, Chen P, Ma K \& Zhou C 2014 Wnt-promoted Isl1 expression through a novel TCF/LEF1 binding site and H3K9 acetylation in early stages of cardiomyocyte differentiation of P19CL6 cells. Molecular and Cellular Biochemistry 391 183-192. (https://doi.org/10.1007/s11010-014-2001-y)

Lyssenko V, Lupi R, Marchetti P, Del Guerra S, Orho-Melander M, Almgren P, Sjogren M, Ling C, Eriksson KF, Lethagen AL, et al. 2007 Mechanisms by which common variants in the TCF7L2 gene increase risk of type 2 diabetes. Journal of Clinical Investigation $\mathbf{1 1 7}$ 2155-2163. (https://doi.org/10.1172/JCI30706)

Marlow H, Matus DQ \& Martindale MQ 2013 Ectopic activation of the canonical wnt signaling pathway affects ectodermal patterning along the primary axis during larval development in the anthozoan Nematostella vectensis. Developmental Biology 380 324-334. (https:// doi.org/10.1016/j.ydbio.2013.05.022)

Mitchell RK, Mondragon A, Chen L, McGinty JA, French PM, Ferrer J, Thorens B, Hodson DJ, Rutter GA \& Da Silva Xavier G 2015 Selective disruption of Tcf712 in the pancreatic beta cell impairs secretory function and lowers beta cell mass. Human Molecular Genetics 24 1390-1399. (https://doi.org/10.1093/hmg/ddu553)

Ni Z, Anini Y, Fang X, Mills G, Brubaker PL \& Jin T 2003 Transcriptional activation of the proglucagon gene by lithium and beta-catenin in intestinal endocrine L cells. Journal of Biological Chemistry 278 1380-1387. (https://doi.org/10.1074/jbc.M206006200)

Norton L, Fourcaudot M, Abdul-Ghani MA, Winnier D, Mehta FF, Jenkinson CP \& Defronzo RA 2011 Chromatin occupancy of transcription factor 7-like 2 (TCF7L2) and its role in hepatic glucose metabolism. Diabetologia 54 3132-3142. (https://doi.org/10.1007/ s00125-011-2289-z)

Norton L, Chen X, Fourcaudot M, Acharya NK, DeFronzo RA \& Heikkinen S 2014 The mechanisms of genome-wide target gene regulation by TCF7L2 in liver cells. Nucleic Acids Research 42 13646-13661. (https://doi.org/10.1093/nar/gku1225)

Savic D, Park SY, Bailey KA, Bell GI \& Nobrega MA 2013 In vitro scan for enhancers at the TCF7L2 locus. Diabetologia 56 121-125. (https:// doi.org/10.1007/s00125-012-2730-y)

Schafer SA, Tschritter O, Machicao F, Thamer C, Stefan N, Gallwitz B, Holst JJ, Dekker JM, t Hart LM, Nijpels G, et al. 2007 Impaired glucagon-like peptide-1-induced insulin secretion in carriers of transcription factor 7-like 2 (TCF7L2) gene polymorphisms. Diabetologia 50 2443-2450. (https://doi.org/10.1007/s00125-007-0753-6)

Shao W, Yu Z, Fantus IG \& Jin T 2010 Cyclic AMP signaling stimulates proteasome degradation of thioredoxin interacting protein (TxNIP) in pancreatic beta-cells. Cellular Signalling 22 1240-1246. (https:// doi.org/10.1016/j.cellsig.2010.04.001)

Shao W, Wang D, Chiang YT, Ip W, Zhu L, Xu F, Columbus J, Belsham DD, Irwin DM, Zhang H, et al. 2013a The Wnt signaling pathway effector TCF7L2 controls gut and brain proglucagon gene expression and glucose homeostasis. Diabetes 62 789-800. (https:// doi.org/10.2337/db12-0365)

Shao W, Wang Z, Ip W, Chiang YT, Xiong X, Chai T, Xu C, Wang Q \& Jin T 2013b GLP-1(28-36) improves beta-cell mass and glucose disposal in streptozotocin-induced diabetic mice and activates cAMP/ PKA/beta-catenin signaling in beta-cells in vitro. American Journal of Physiology: Endocrinology and Metabolism 304 E1263-E1272. (https:// doi.org/10.1152/ajpendo.00600.2012)

Shao W, Xiong X, Ip W, Xu F, Song Z, Zeng K, Hernandez M, Liang T, Weng J, Gaisano H, et al. 2015 The expression of dominant negative TCF7L2 in pancreatic beta cells during the embryonic stage causes impaired glucose homeostasis. Molecular Metabolism 4 344-352. (https://doi.org/10.1016/j.molmet.2015.01.008)

Shigeto M, Ramracheya R, Tarasov AI, Cha CY, Chibalina MV, Hastoy B, Philippaert K, Reinbothe T, Rorsman N, Salehi A, et al. 2015 GLP-1 stimulates insulin secretion by PKC-dependent TRPM4 and TRPM5 activation. Journal of Clinical Investigation 125 4714-4728. (https:// doi.org/10.1172/JCI81975) 
Shu L, Matveyenko AV, Kerr-Conte J, Cho JH, McIntosh CH \& Maedler K 2009 Decreased TCF7L2 protein levels in type 2 diabetes mellitus correlate with downregulation of GIP- and GLP-1 receptors and impaired beta-cell function. Human Molecular Genetics 18 2388-2399. (https://doi.org/10.1093/hmg/ddp178)

Shu L, Zien K, Gutjahr G, Oberholzer J, Pattou F, Kerr-Conte J \& Maedler K 2012 TCF7L2 promotes beta cell regeneration in human and mouse pancreas. Diabetologia 55 3296-3307. (https://doi. org/10.1007/s00125-012-2693-z)

Soltani N, Qiu H, Aleksic M, Glinka Y, Zhao F, Liu R, Li Y, Zhang N, Chakrabarti R, Ng T, et al. 2011 GABA exerts protective and regenerative effects on islet beta cells and reverses diabetes. PNAS 108 11692-11697. (https://doi.org/10.1073/pnas.1102715108)

Takamoto I, Kubota N, Nakaya K, Kumagai K, Hashimoto S, Kubota T, Inoue M, Kajiwara E, Katsuyama H, Obata A, et al. 2014 TCF7L2 in mouse pancreatic beta cells plays a crucial role in glucose homeostasis by regulating beta cell mass. Diabetologia 57 542-553. (https://doi.org/10.1007/s00125-013-3131-6)
Takeda Y, Shimayoshi T, Holz GG \& Noma A 2016 Modeling analysis of inositol 1,4,5-trisphosphate receptor-mediated Ca2+ mobilization under the control of glucagon-like peptide- 1 in mouse pancreatic beta-cells. American Journal of Physiology: Cell Physiology $\mathbf{3 1 0}$ C337-C347. (https://doi.org/10.1152/ajpcell.00234.2015)

Tian L \& Jin T 2016 The incretin hormone GLP-1 and mechanisms underlying its secretion. Journal of Diabetes 8 753-765. (https://doi. org/10.1111/1753-0407.12439)

Wu B, Wei S, Petersen N, Ali Y, Wang X, Bacaj T, Rorsman P, Hong W, Sudhof TC \& Han W 2015 Synaptotagmin-7 phosphorylation mediates GLP-1-dependent potentiation of insulin secretion from beta-cells. PNAS 112 9996-10001. (https://doi.org/10.1073/ pnas.1513004112)

Zhou Y, Park SY, Su J, Bailey K, Ottosson-Laakso E, Shcherbina L, Oskolkov N, Zhang E, Thevenin T, Fadista J, et al. 2014 TCF7L2 is a master regulator of insulin production and processing. Human Molecular Genetics 23 6419-6431. (https://doi.org/10.1093/hmg/ ddu359)

Received in final form 6 March 2018

Accepted 29 March 2018 